them to consider its deliberations before setting their fMRI data policy.

So far, few have followed the Journal of Cognitive Neuroscience's lead. Indeed, none of those named in Gazzaniga's letter have adopted a policy of mandatory submission to the National fMRI Data Center.

Other researchers argue that the issues run deeper than scientists' control of their data. Peter Fox, of the University of Texas Health Science Center in San Antonio, notes that individuals could be identified from the anatomical data requested by Gazzaniga. "It's quite easy to make a 3D model of the face," says Fox, who is working with the US Department of Justice on the potential of fMRI data in forensics.

The National fMRI Data Center's instructions for data submission acknowledge these concerns. "We can provide security measures," says a memo dated 21 June. "We'll be developing algorithms," adds Gazzaniga. But Fox is concerned that the centre has not consulted widely enough. "We put in phone calls, and they weren't returned," he says.

"There was no attempt at exclusion," responds Gazzaniga. "But if there'd been a phone call or two that would have made everyone feel better, we should have done it." Gazzaniga claims that the current controversy has done the field a service by sparking debate on data sharing. "We're provoking some thought," he says.

http://www.fmridc.org

http://www.psy.vanderbilt.edu/faculty/

gauthier/fmridc_letter.htm|

http://www.nmr.mgh.harvard.edu/OHBM

\title{
UK hopes that big-money deals will attract top talent
}

\section{Natasha Loder, London}

Positions vacant: world-class researchers sought. A combined salary top-up and discretionary grant of up to $£ 100,000$ (US\$150,000) available. Apply to Her Majesty's Government.

For years, Britain has worried about both attracting and keeping top scientists. In the 1960s the Labour government even thought about banning foreign job advertisements or treating scientists as an élite group (see Nature 403, 121; 2000). The hook has now been baited with money. The idea is that, like sports stars, 50 of the world's leading academics will be tempted to transfer to Britain.

The announcement of the new fund coincides with the release of a white paper in which the government says that Britain needs to attract more scientists and engineers from overseas, and promises to change the immigration rules to make it easier for students and foreign researchers to work and remain in the country.

The salary top-ups are being offered by the UK government, the Wolfson Foundation and the Royal Society - whose fellows have been taking jobs abroad at an increasing rate (see graph). The government will contribute half of an annual $£ 4$ million fund.

But the government has offered few details about how the scheme would work, or

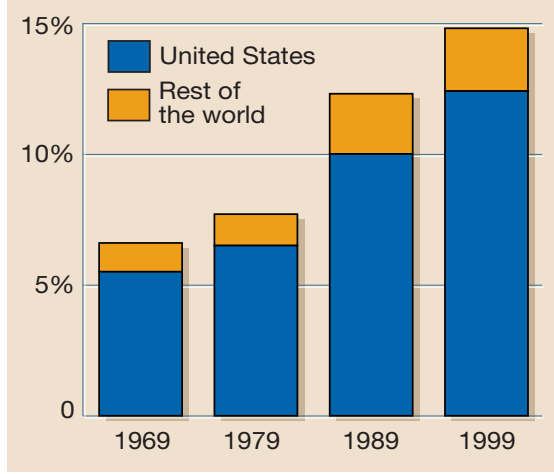

Brain drain: a growing proportion of Royal Society fellows work outside Britain.

how long the fund would last. The Royal Society says it intends to make a "long-term commitment". And a panel that includes scientists from the society, the Wolfson Foundation and the Royal Academy of Engineers will be set up to seek out scientists in key areas of research.

Eric Ash, treasurer of the Royal Society, a trustee of the Wolfson Foundation, and one of those behind the scheme, says that the fund would offer money on top of the standard salary offered by the university. "Our feeling is that it won't all be salary. Part of it could be discretionary research grant, which is the hardest thing to get hold of."

\section{Science may lose out from sale of 'flying reptile' fossil}

\section{Jessa Netting, Washington}

The imminent auction of a fossilized gliding reptile that lived 200 million years ago has fuelled concern among palaeontologists

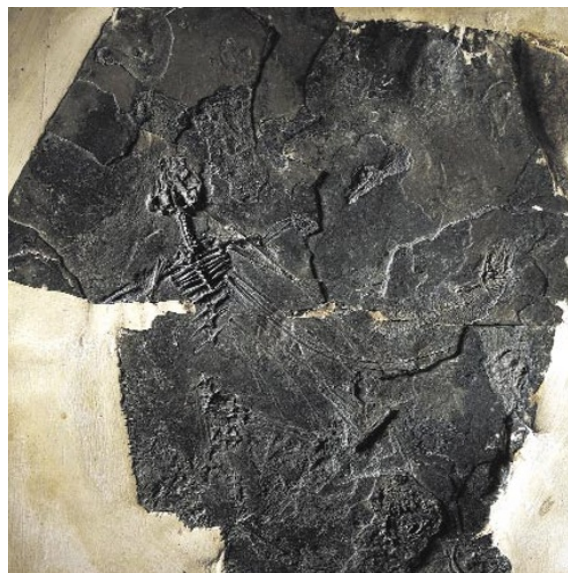

Going, going, gone? The auctioning of Icarosaurus may cause it to disappear from researchers' sight. about the impact of private collectors on their scientific work.

The fossil, Icarosaurus siefkeri, was discovered by Alfred Siefker, who, with the help of two teenage friends, dug it out of an abandoned quarry in 1961. It was housed in the American Museum of Natural History in New York until ten years ago, when Siefker reclaimed it and offered it to the museum and other institutions for $\$ 5$ million.

The offer was not taken up. Now in ill health, Siefker has dropped the price and opened the bidding to private collectors. The fossil is being auctioned by Butterfields in San Francisco at the end of this month, and is expected to raise $\$ 250,000-\$ 300,000$.

When discovered, the $18-\mathrm{cm}$-long Icarosaurus was the oldest known example of a reptile that had taken to the air, preceding the pterosaurs and birds by as much 50 million years. Its $25-\mathrm{cm}$ wingspan did not allow powered flight, only gliding.

Palaeontologists have since described an older gliding reptile, Weigeltosaurus. Despite this, the rarity of 'flying' reptiles, and the fact that Siefker's fossil is the 'type specimen' - the first of its species to be described - make it scientifically valuable.

The prospect of such a fossil falling into private hands has set alarm bells ringing.

"The reaction of most people is one of horror," says Mary Dawson, curator of vertebrate palaeontology at the Carnegie Museum of Natural History in Pittsburgh, Pennsylvania. "It would be all right if it goes to a museum, but if not it [could be] lost to science."

David Herskowitz, Butterfields' naturalhistory specialist, is less pessimistic. "If a person is going to pay enough to put it in their collection, you can be sure when that person dies, it will be donated to a museum," he says. "We are really hoping that they can find a trustee who will pay for it and donate it back to the American Museum in New York.” 